\title{
Inpatient Non-acute Care Encounter
}

National Cancer Institute

\section{Source}

National Cancer Institute. Inpatient Non-acute Care Encounter. NCI Thesaurus. Code C150755.

An inpatient encounter for a non-acute condition. 